\title{
Tense and Modality in Nominals
}

\author{
Jacqueline Lecarme \\ Laboratoire de Linguistique Formelle \\ UMR 7110 CNRS-Université Paris VII*
}

November 2007

\begin{abstract}
It has been shown that, at least in certain languages, tense is represented in nominals (Lecarme 1996, 2004). It is therefore important to consider whether the interplay between tense and modality which is commonly found in clauses exists in the nominal domain as well. This article investigates the non-temporal meanings of nominal tenses in Somali, an Afroasiatic language. It explores the conditions under which nominal past morphology is interpreted in the modal dimension, contributing either a quantificational reading of the past DP (comparable to English -ever in e.g., 'whenever') or an evidential reading focusing on the visible / non-visible distinction. It is argued that the common abstract feature underlying the various meanings of past morphology in nominals is a more primitive feature of "exclusion/dissociation" (Iatridou 2000). To account for the link between direct evidentiality and visual perception in nominals, it is proposed to extend Kratzer's $(1981,1991)$ theory of 'doubly relative' modality to include a perceptual component. In this revised framework, past morphology gives rise to 'non-actual', 'unknown' or 'invisible' modal meanings, depending on different choices of modal base and ordering source.
\end{abstract}

Keywords tense, modality, evidentiality, determiners, visual perception.

\section{Introduction $^{1}$}

The modal use of a past morphology (e.g., in conditional or hypothetical clauses) is a well attested phenomenon in natural language. Informal treatments suggest that past tense does not receive a temporal interpretation, but rather expresses a modal 'displacement'. Iatridou (2000) proposes that a unified account of temporal or modal displacement can formally be construed as a set-theoretic exclusion/dissociation relation between a topic time or world and a speaker time or world. In her terms, past morphology realizes an

\footnotetext{
* To appear in J. Guéron and J. Lecarme (eds), Time and Modality, Studies in Natural Language and Linguistic Theory, Springer (Dordrecht).

${ }^{1}$ This chapter develops ideas outlined in Lecarme (2003), and is based on material presented at the DIP Colloquium (University of Amsterdam, October 2003), the 27th GLOW Colloquium (Aristotle University of Thessaloniki, April 2004) and the International Round Table on Tense, Aspect and Modality (Universités Paris 7 and Paris 3, December 2005). I wish to thank the participants at those events. I am particularly indebted to Jacqueline Guéron for valuable written comments on an earlier version, and to Bascir Kenadid (Bashiir Nuur Keenadiid) for insightful discussion of the Somali data.
} 
'exclusion' feature whose meaning in the temporal domain is that the topic time (i.e., the time interval (set of times) we are talking about) excludes the utterance time, and whose meaning in the modal domain is that the topic worlds exclude the speaker's actual world. Izvorski (1997) takes the same approach in her pioneering study of (indirect) evidentiality, suggesting that the 'exclusion' mechanism interacts with more specific domains of modality, such as the linguistic expression of a speaker's source of knowledge (or information).

The purpose of this article is to support such accounts, by providing a new perspective. More concretely, I argue that the interaction of tense, modality and evidentiality has a natural parallel in the nominal domain. My study is based on Somali, an East Cushitic language where nominals display an elaborate tense system ${ }^{2}$. In the present article, I investigate more precisely the non-temporal meanings of nominal tenses, and show how a nominal past, in addition to being a temporal item, displays properties of a modal item (e.g., apparently contributing a quantificational reading of the past DP), or an evidential item (contributing the visible/non visible distinction).

I will approach the issue from two perspectives: (i) Under which conditions is a past nominal interpreted in the modal dimension? and (ii) Can we give a unified account of nominal pasts in their temporal, modal, and evidential meanings?

Our discussion will be in three parts. First, I introduce an account of the phenomenon, and discuss the sense in which it can be thought of meaningfully as deserving the designation 'nominal tense', that is, 'grammaticalized location in time' by Comrie's (1985) definition. Second, I turn to a discussion of generic/habitual sentences, as well as adverbial and conditional clauses in the present tense, where the nominal past morphology is interpreted not along a temporal, but along a modal dimension. I show that the numerous instances of the interaction of the past tense with the modal domains, for which we have a wide crosslinguistic evidence, have systematic parallels in nominals. This will lead us to the third issue, the use of a nominal past as a direct (i.e., perceptual) evidential. I will explore the possibility that Kratzer's (1991) notion of 'doubly relative' modality might lead to a unified analysis of the tense/direct evidentiality connection, offering, at the same time, a perspective to explain the core facts presented here in a consistent way.

\section{Tense in nominals}

\subsection{Space and time}

To appreciate the role of nominal tense marking in Somali syntax and semantics, it is necessary to introduce some of the basic features of the determiner system (see Lecarme, 1996, 2004).

\footnotetext{
${ }^{2}$ See Lecarme (1996, 1999b, 2003, 2004). 'Nominal tense' is a well attested morphological phenomenon (see Nordlinger and Sadler (2004) for typological investigation from a wide-ranging survey of languages where the phenomenon occurs). Further elaboration depends on a fine-grained syntactic analysis of the relevant structures and the sentences in which they occur. If the 'temporal markers' in some languages are actually nominal aspect, not nominal tense, as argued by Tonhauser (2006) for Guaraní, then we might expect languages to allow tensed, aspectual, or tenseless nominals, a further parallel with clauses.
} 
Both the definite article ${ }^{3}$ and the demonstrative enclitics appear suffixed to the noun (in both cases, the initial consonant- $k$-/-t- is a gender morpheme which agrees with the noun). Somali demonstratives mark distance in space relative to the speaker, encoding a four-way distinction in proximity with regard to the speech act (1).

(1) Spatial demonstratives:

-k/t-án 'this, these'

-k/t-áas 'that, those'

-k/t-éer 'that, those'(visible middle distance)

-k/t-óo 'that, those yonder' (far away, still visible)

Besides this, Somali and the closely related East Cushitic languages have a morphology specific to the temporal domain (2). The Somali nominal tense system is, basically, the morphological encoding of past and nonpast (present or generic), which surfaces as a vocalic $i / a$ opposition also found in the verbal system in most Afroasiatic languages. As discussed in Lecarme (1996), the relevant opposition has to be understood as i/ Ø, $a$ being the unmarked, 'default vowel' in Afroasiatic ${ }^{4}$.

(2) Tensed definite article:

$\begin{array}{lll} & \text { [-past] } & \text { [+past] } \\ \text { [+nom] } & -\mathrm{k} / \mathrm{t}-\mathrm{u} & \mathrm{k} / \mathrm{t}-\mathbf{i i} \\ \text { [-nom] } & -\mathrm{k} / \mathrm{t}-\mathrm{a} & \mathrm{k} / \mathrm{t}-\mathbf{i i}\end{array}$

Demonstratives and definites can cooccur: nín-kan- $u$, 'this man', baabúur-taas- $i$ 'those trucks' shíl-kaas-i 'that accident'. As in other languages with complex determiners (e.g., Germanic), 'double definiteness' has the effect of an intensifier'.

From the fact that both demonstratives and tensed definite articles can be used deictically, should we conclude that they belong to the same category, 'deictics'? There are several important points worth noting here. First, Somali demonstratives, unlike English this and that, never lose their (deictic) spatial function. Even in their anaphoric uses (e.g., in texts), the demonstratives -an and -aas remain demonstrative in that they pick up a referent in a set whose salience is determined spatially. Second, demonstratives (universally) do not function in 'narrow syntax ${ }^{6}$, only in interpretation of the information they

\footnotetext{
${ }^{3}$ In Standard Somali, no indefinite article appears on the surface: a man is expressed with the Somali equivalent of man (the indefinite form can mean either non-specific or specific indefinite).

${ }^{4}$ In Lecarme (1996, 1999b), the suffixed definite forms are derived by syntactic N-to-D movement. A morphological merger analysis of the sort developed by Embick and Noyer (2001) would rather treat these cases as involving Lowering the entire $\mathrm{D}$, which is internally complex, to the head of its NP complement, leading to a parallel morphological structure root- $\phi$-tense for both the tensed nominal and verbal forms. See Lecarme (2004, 343-344) for more details.

${ }^{5}$ This distributional fact is generally not mentioned in the literature (but see Kirk (1905) for a thorough description, based on the Isaaq dialect of Somali). Since the relevant DPs can occur in non-subject position, the past ending is not to be assimilated to the $-i$ nominative morphology which is marked at the right edge of the phrase under certain conditions (see Anderson et al. (2006) for a recent analysis). Assuming that Somali $\mathrm{D}$ is $\varnothing$ with gender agreement and tense incorporated to D (T-to-D), the relative order of the possessive and demonstrative enclitics suggests that demonstratives are merged higher than Spec,TP (presumably, Spec,DP). A full account of how this hierarchical structure is linearized is beyond the scope of this article.

${ }^{6}$ Narrow syntax is taken here as the core recursive aspect of the language faculty (Chomsky, 1995, and subsequent work).
} 
provide: there are no locative elements corresponding to tenses. Somali tense morphology is inflectional, and determines crucial aspects of the narrow syntax of DP. Third, unlike English that/those-phrases, which can have narrow scope readings, Somali demonstratives are scopally inert. Past DPs are able to take narrow scope with regard to operators and quantifiers. I will examine the last two points in more details below.

\subsection{The D-T relation}

Tense-marking on nominals is an inescapable feature of Somali grammar. Understanding the past/nonpast opposition marked on the definite articles is part of the basic linguistic competence of Somali speakers. As I discussed elsewhere (Lecarme, 1996, 1999b, 2003, 2004), nominal tense is independent of clausal tense, even if they generally coincide (or overlap). This effect is very sharp in relative clauses, where the tense of the antecedent DP need not be the same as the tense of the relative clause. For example, a nonpast DP is characteristically used, as in (3a), when the referent is a famous person, or when the speaker wants to discuss a person or thing in the context of the utterance $(3 b, c)$. Here and below, the absence of explicit gloss uniformly indicates a nonpast nominal morphology (whether interpretable or not as a present tense) $)^{7}$.

a. Nín-ka cáan-ka ah ee búug-gani qoray (waa man-defM. fame-defM be and book-defM.dem.past wrote[+nom] F/C Shákisbíir)

Shakespeare

'The famous man who wrote this book (is Shakespeare)'

b. Ma ógtahay qóf-ka aan ú codeeyay?

Q know.2s person-defM 1S for vote.past

'Do you know whom I voted for?'

c. Arrín-ta Xámar i keentáy (baan ku shéegayaa)

affair-defF Mogadishu 1S brought F.1S 2S tell.prog

'(I am telling you/ going to tell you about) the affair which brought me to Mogadishu'

It appears, then, that both nominal and verbal/clausal tenses are computed in relation to the speech time. Thus, assuming that the definite article is a D(eterminer) heading a DP (determiner phrase), the domain of interpretation of the tense marked on D is the DP. In previous work, I proposed that parallel to the C-T relation expressing clausal finiteness,

\footnotetext{
${ }^{7}$ The examples in the article follow the national orthography with small modifications: the main tonal accent of a prosodic word is noted with an acute accent; hyphens are added for morpheme separation. Key to Somali gloss: $\mathrm{C} / \mathrm{F}=$ complementizer/'focus marker' (I analyze the baa/waa morpheme as a declarative root complementizer); defF/M = definite feminine / masculine article, dem = demonstrative, dep. = dependent, dir. $=$ directional particle, expl $=$ expletive, gen $=$ general $/$ generic, Poss $=$ possessive, prog. $=$ progressive, neg. $=$ negation, restr. = restrictive agreement. Pronominal clitics are identified by their person, gender, and number features (upper cases). Referential third object pronouns are $\varnothing$ in Somali. Low cases = agreement features. Most examples in the text are from my previous papers, from Shabeelnaagood (a Somali play by Hassan Sheikh Mumin), from the BBC Somali Service, and from Google.
} 
there is a D-T relation expressing 'nominal finiteness' ${ }^{8}$. For the purpose of the present article, I will assume that DPs have a structure (4), where D is formally parallel to C, $\mathrm{n}^{*}$ is parallel to $\mathrm{v}^{*}$ and selects the 'external' (possessor) argument, $\mathrm{n}$ is a light noun, and NP, $\mathrm{n} * \mathrm{P}$ and DP define three syntactic domains for tense interpretation ${ }^{9}$ :

\section{(4) [DP D [Tе T [n*P $\left.\left.\left.\mathrm{n}^{*}[\mathrm{nP} \mathrm{n}[\mathrm{NP} \mathrm{N}]]\right]\right]\right]$}

This hypothesis immediately accounts for the fact that the past determiners are scope bearing elements with regard to the interpretation of modifiers. Like English before, the (non-intersective) adjective horé 'before' is a general ordering predicate that situates or characterizes an entity in either time or space from a reference point. As the examples show, horé has a spatial meaning when used with a spatial demonstrative (5a) or a present nominal tense (5b), and a temporal meaning in the domain of a nominal PAST: in other words, PAST is required for horé be interpreted as 'former' (5c). In contrast, only a present nominal is compatible with a modifier like máanta 'today'. This is best illustrated by (5d).

(5) Spatio-temporal modifiers

a. Tuulá-dóo horé (éeg!)

village-defF.dem before look

'(Look at) that village in front!'

b. Jíd-ka hore má ahan ee waa kán labaad street-defM before Neg is and F/C m.dem second 'It is not the next street ahead, but the second one'

c. (Waa) tuulá-díi hore (oo aad degganayd)

$\mathrm{C} / \mathrm{F}$ village-defF.past before (and $2 \mathrm{~S}$ lived.2s)

'(This is) the former village (where you lived)'

d. Máxay kú kala duwán yihiin noló-shíi dád-kíi hore What.3P at between different are.3p life-defF.past people.defM.past before iyo tán dád-ka maánta? and f.dem people-defM today In what does the life of former people differ from the one of today's people?

Nominal tense is 'inflectional' in Somali in that the D-T complex determines crucial aspects of the internal syntax of DP, such as Case assignment, agreement and deletion processes (Lecarme, 1996, 1999b, 2004). I argued that structural genitive Case involves T in

\footnotetext{
${ }^{8}$ I envisage a parallel treatment of CP and DP, as often implied in the literature (see Hiraiwa, 2005, for a recent syntactic account). On the semantic side, many parallels have been suggested between nominals and clauses: verbs in general are assumed to have neo-Davidsonian meanings, where the VP names a 'property of eventualities (events and states, cf. Bach (1981)), not a single event. Events are assumed to have the same logical type as individual entities, that is, $\langle\mathrm{e}\rangle$. 'Sentence determination' is obtained by quantifying over the event variable (Krifka, 1992; Partee, 2000; von Stechow, 2002). Building on these studies, I will assume that noun phrases, like sentences, contain implicit quantification over times, and implicit restrictions to times contained in a contextually salient interval.

${ }^{9}$ The functional head $\mathrm{n} *$ is labelled Appl(icative) in Lecarme (2004).

In the following, I will use 'tense' as 'morphological tense' (possibly null), $\mathrm{T}$ as the syntactic category $\mathrm{T}$ (ense), the locus of computation of tense features ([T]), and PAST as semantic tense (some abstract temporal quantifier).
} 
addition to D: elements with inherent case selected by $\mathrm{n} *$ remain in Spec, $\mathrm{n} * \mathrm{P}$, pronominal possessors in Spec, TP are assigned Case by $\mathrm{T}$ in conjunction with $\mathrm{D}$. Tense also can be used as a feature of agreement (or concord). As (6) shows, Somali adjectives must agree with a definite head noun in gender and tense ${ }^{10}$.

(6) Tense agreement (adjectives)

a. Xaashí-da yar ee cád (buu kéenayaa) paper-defF small and white (F/C.3MS is.bringing) '(He is bringing) the small white sheet of paper'

b. Xaashí-díi yarayd ée caddayd (buu keenay) paper-defF.past small.past.f and white.past.f (F/C.3MS brought) '(He brought) the small white sheet of paper'

At the same time, Somali (among other Afroasiatic languages) has a syntactic condition to the effect that noun modifiers in the context of $\mathrm{D}_{\text {[Definite] }}$ must be marked morphologically for definiteness.

(7) Tense and definiteness agreement (NP modifiers)

a. ardayád soomaalí ah student.f Somali.f be 'a Somali student(f)'

b. Ardayád-da Soomaalí-da ah (way imáaneysaa) student.f-defF Somali-defF be (C/F.3F is.coming.f 'The Somali student(f) (is coming)'

c. Ardayád-díi Soomaalí-da ahayd (wáy timid) student.f-defF.past Somali-defF be.past.f (C/F.3F f.came) 'The Somali student(f) (came)'

In uttering (6b), the language user does not assert that the smallness and whiteness of the sheet of paper is 'past' relative to the utterance time: if that were the case the use of past tense would be at best unfelicitous, as under the most natural interpretation the state of the sheet of paper being white and small extends through the time of utterance into the future. Similarly, the use of past in (7c) does not mean that the individual-level predication 'be Somali' held of the student (only) prior to the utterance time ${ }^{11}$. In addition, the DP modifier in $(7 \mathrm{~b}, \mathrm{c})$ is not interpreted as a definite description. The most telling examples are idioms, since idioms typically do not have compositional meanings. The paradigm for an idiomatic noun+ adjective combination thus will be as follows:

(8) Idioms

a. siyaasadó foól xun policies face ugly 'ugly policies' (lit. 'ugly-face' policies)

\footnotetext{
${ }^{10}$ On the special morpho-syntactic status of nominal number, see Lecarme (2002).

${ }^{11}$ On the syntactic and semantic difference between adjectives (white) and stative verbs (be white), and between inflected adjectives/predicative nouns and (reduced) relative clauses in Somali, see the discussion in Lecarme (2004).
} 
b. siyaasadá-ha foó-sha xun policies-defM face-defF ugly 'the ugly policies' (lit. 'the face')

c. siyaasadí-híi foó-sha xum-aa ee uu guméysi-gu policies-defM.past face-defF ugly.past and 3SM colonialist-defM[+nom] doónayey ínuu... wanted COMP.3MS

'the ugly policies with which colonialists wanted to...'

Space prevents me from reviewing all the evidence. What is important here is simply the overall generalization: nominal Tense, like Definiteness, is interpreted syntactic material. [Definite] and [T] pattern together because they are both features on D. Agreement morphemes reflect certain syntactic properties, but do not in any sense contribute these properties to syntax. Assuming the recent minimalist framework (Chomsky, 1995, 2000 , 2001), these instances of past tense represent unvalued features $(u T)$ that must be valued valued at the D-phase level, in a local relation to an interpretable PAST (the D-T connection).

\subsection{Time and the noun}

\subsubsection{On tense morphlogy and temporal interpretation}

Assuming that syntax and semantics run in parallel from the bottom to top, three (sets of) times are potentially involved in the temporal interpretation of noun phrases: (i) the time of the predicate (or predication time), that is, the times at which a property like 'dog' or 'president' is asserted to hold of an individual, (ii) the time of the genitive/possessive relation 'R' (Higginbotham, 1983b; Partee, 1983), and (iii) the time of (existence of) the individual $^{12}$. The corresponding syntactic domains are NP, $\mathrm{n} * \mathrm{P}$ and DP, respectively. The relevant Somali examples are as follows:

(9) a. Madaxweyní-híi hore (wuu imaáneyaa) president-defM.past before C/F.3SM is.coming 'The former president (is coming)'

b. (Wáxaan ku bárayaa) afáday-díi hore expl.C/F.1S 2S introduce.prog wife-defF.Poss1S-defF.past before '(I am introducing to you) my ex-wife'

c. Weerár-kíi ków iyo tobán-kíi Sebtémber (ma lá socotaa?) attacks-defM.past one and ten-defM.past September Q with follow.2s '(Do you know about) the September 11 attacks?'

\footnotetext{
${ }^{12} \mathrm{Here}$ and below, I assume that there is no asymmetry between the application of tense to individuals and to events. The individual's 'time of existence' is to be understood as the time associated with underlying existential quantification (making the temporal location of an individual parallel to the temporal location of an event), not the whole time-span of an individual's existence, which is, in case of animate individuals, their lifetime (Kratzer, 1995; Musan, 1995, 1997).
} 
As discussed in section 1.2, the spatio-temporal adjective horé, like English before, express temporal precedence when it is bound by a PAST tense. In (9a), horé applies to the predicate, creating a predicate true of individuals that once had the property 'president' (horé is needed to convey the aspectual meaning of ex- or former). In (9b), horé applies to the possession relation: the nominal can be used to refer to someone who was formerly 'my wife', and is 'my wife' no longer. As our examples make it clear in both cases, the time when the property 'president' or 'my wife' is true of the individual must be a subset of the intervals bound by horé, but in order for those intervals to be temporally located in the past, a nominal PAST is needed. Similarly, in (9c), the running time of the event (the attacks) must be included in the reference time (September 11). The effect of a nominal PAST is to constrain the denotation of the temporal modifier 'September 11' to a set of past times. Nominals then are much similar to clauses with regard to temporal interpretation: PAST makes it possible to chain together various elements of the interpretation of noun phrases. Since the core eventuality is anchored at the utterance time, there is no other source of PASTness in our examples.

\subsubsection{On the temporal location of individuals}

Most of the previous work on the temporal interpretation of noun phrases (in English and German) has centered on the temporal location of predication times. ${ }^{13}$ We owe to Enç (1981) the claim that the interpretation of fugitives in sentences such as 'every fugitive was in jail' is independent of the tense that is present in the syntax (the possible readings involve individuals who are fugitives now, or were fugitives before they were in jail). Enç (1986) proposed that nouns (like verbs) must be provided with temporal arguments, the value of which are supplied by the utterance context. Important observations made by Musan (1995) led her to question this analysis. According to her, the correct generalization is that only strong (presuppositional) NPs are temporally independent. Cardinal noun phrases (e.g., weak noun phrases in existential there-constructions) can have temporally dependent readings.

The temporal location of individuals has received comparatively little attention. Musan $(1995,1997)$ does provide a pragmatic account of the 'lifetime effects' that individuallevel predicates like 'be from America' or 'have blue eyes' impose to their subjects ${ }^{14}$. But Musan's theory aims at explaining in which way the temporal location of individuals is determined or affected by the temporal interpretation of a clause, and crucially depends on an ontology that contains stages (temporal parts) of individuals as basic entities (of type e). On this view, an individual's 'time of existence' is actually the time of existence of a stage of an individual.

Deeper insights into the temporality of noun phrases, I argued, can be gained by the study of systems where nominals encode temporal distinctions. In Somali, tense is a feature of any (common) noun, not only nouns that are said to include an event as part of their lexical semantics. The main function of nominal tense in the language is to temporally

\footnotetext{
${ }^{13}$ On the temporal location of the genitive/possessive relation, see Burton (1997), Larson and Cho (1999, 2003).

${ }^{14}$ See note 12 above.
} 
locate individuals like the table and my brother ${ }^{15}$. Syntactic Definiteness and Tense draw the difference between the 'strong' pronouns, which have the same distribution as ordinary DPs, and the 'weak' pronouns (semantically definite) associated with them. Since pronouns do not contain nouns that can be predicated of a stage, the following examples illustrate a clear case where nominal tense locates an individual temporally, at a past time which overlaps (or coincides with) the time of the event:

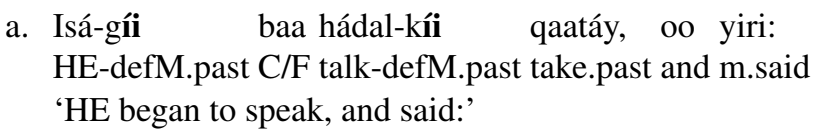

b. Díbna umá arág isá-gíi iyo lacágtay-diiba.

Back.any at.NEG see HIM.defM.past and money.f.Poss1S-defF.past.any 'Afterwards I did not see HIM again, nor my money'

Both Enç's and Musan's generalizations can be derived from the nominal tense hypothesis. Assuming that the time variables of nominals are bound DP-internally by a nominal tense operator, the scope paradoxes that motivated Musan's stage analysis do not arise $^{16}$. The cardinal vs. presuppositional distinction is tense-related: if true D (i.e., D+T) relates to referentiality in some sense, an indefinite nonspecific nominal phrase ('a lot of people', 'someone', etc.) is temporally indefinite. A crucial piece of evidence for this is that nonreferential nominals (nonspecifics, quantified and predicate nominals, etc.) are tenseless in Somali. On this view, the distribution of temporally dependent/independent noun phrases coincides closely with Chomsky's (2000; 2001; to appear) notion of phase: weak (temporally indefinite) NPs are merged in the VP and interpreted in situ, whereas 'presuppositional'(i.e, tense-related) DPs occupy higher positions in the syntax ${ }^{17}$.

\subsection{Interim discussion}

To recapitulate the conclusions so far, crucial aspects of temporal interpretation of nominals in Somali are strictly determined by linguistic form, then belong to the syntax and semantics of the language. Depending on the tense marked on the DP, (simple) event and process nominals (e.g. exhibition, trip, ceremony) trigger distinct presuppositions, as reflected by the English translations of the examples.

(11) Presuppositions

a. Bandhíg-ga máad daawatay?

exhibition-defM Q.2S see.2s.past

'Have you seen the exhibition?' (still running at UT)

\footnotetext{
${ }^{15}$ As expected, proper names, kind-denoting DPs (e.g. naasleý-da 'the mammal(s))' and DPs that denote abstract entities (e.g. xisaáb-ta 'the mathematics') do not reflect tense distinctions.

${ }^{16}$ See Musan's (1995, 89-92) arguments against a scope approach of the presuppositional vs. cardinal distinction (Diesing, 1988, 1992), namely that presuppositional noun phrases under the scope of a temporal adverb of quantification still can be temporally independent.

${ }^{17}$ In the framework of Chomsky (2001, to appear), a DP with an interpretable tense feature should reach the edge position of the phases $\mathrm{V}^{*} \mathrm{P}$ and $\mathrm{CP}$ (i.e., outer Spec, $\mathrm{v}^{*}$ and $\mathrm{Spec}, \mathrm{T}$, if $\mathrm{T}$ inherits the edge feature of $\mathrm{C}$ ) typically associated with 'surface structure' interpretation (specificity, new/old information, topicality, etc.).
} 
b. Bandhíg-gíi máad daawatay?

exhibition-defM.past Q.2S see.2s.past

'Did you see the exhibition?' (closed at UT)

Both utterances (11a) and (11b) carry an existence presupposition: the sentences would be used most naturally by a speaker who assumes that the hearer knows that there is a (unique) exhibition - the semantic contribution of the definite article. A second presupposition is associated with tense: by uttering (11b), a speaker makes it clear that she takes for granted that the exhibition is 'over' at the time of her utterance. The temporal presupposition is not required to be in the common ground ${ }^{18}$. The presuppositional content is not an implicature either, since conversational implicatures are typically cancellable. The presuppositional fact encoded in the linguistic meaning of nominal expressions-namely that the exhibition is 'past' or 'present' relative to the time of utterance - is semantic in the sense that it represents what the speaker knows, independently of her communicative intention.

On the assumption that the semantic conditions on the temporal interpretation of noun phrases are similar across languages, what distinguishes, say English (or German) from Somali? One possibility is that in languages where the temporal interpretation of nominals does not show up in linguistic form, these temporal interpretations are pragmatic, not semantic. They are accordingly not represented. A more plausible possibility is that the English DP reaches the semantic interface in the same form as the Somali DP, as we would expect if the external systems of interpretation are essentially language-independent. On this view, the temporal arguments of nouns are represented in the syntax as empty categories sensitive to their syntactic environment. Perhaps supporting this conclusion is that nominal tense features are also often phonologically expressed in some fashion. According to Pesetsky and Torrego (2001), the property of nominals called 'structural case' is actually unvalued T on D. Determiners across languages are semantically complex elements with inner structure. Languages with 'double definiteness' effect provide some evidence that definiteness is comprised of two parts: uniqueness and specificity (in the sense of Enç, 1991) ${ }^{19}$. In their anaphoric uses, non-proximal demonstratives (e.g., English that/those) are prone to semantic reinterpretations in which the basic deictic meaning has been lost. It is likely that the language faculty does not stipulate which features serves as the past 'exclusion' function in the nominal domain. It merely requires some feature of $\mathrm{N}$ to perform this function.

\footnotetext{
${ }^{18}$ See Lecarme $(1996,1999 b)$ for more examples. The fact that the temporal presupposition is not required to be in the common ground makes it more similar to assertions than a presupposition under a Stalnakerian analysis, although the presupposition is not directly asserted. This, however, is left for future discussion.

${ }^{19}$ Roehrs (2006, on Scandivian) makes the interesting claim that 'specificity' originates in a syntactic position lower than $\mathrm{D}$, and that determiners are parallel to auxiliaries in the clause.
} 


\section{Modality}

\subsection{Time and worlds}

Crosslinguistically, past tense morphology often does not indicate temporal anteriority (e.g., in English and Japanese, the non-temporal use of a past tense carries a definitive meaning of counterfactuality). Most linguists think that these different uses are closely related and are not merely uses of distinct homonymous lexical items. This lends support to Iatridou's (2000) idea that past tense is used as an exclusion/dissociation feature, formally expressed as (12).

(12) $\mathrm{T}(\text { opic) })_{\mathrm{x}}$ excludes $\mathrm{C}_{\mathrm{x}}$

The variable $x$ ranges over times or worlds (Iatridou 2000,246)

When the variable ranges over times, past tense expresses a relation of precedence between the Topic Time (Klein, 1994) and the Utterance Time. When the variable ranges over worlds, past tense morphology allows the set of topic worlds to excludes the actual world, thus establishing the implicature of counterfactuality.

In this section, I argue that the analysis naturally extends to the nominal domain: nominal past is among the devices that make it possible to get access to non-actual worlds for the interpretation of noun phrases. I describe how the generic operator interacts with definite expressions, using first ordinary definites and then free relative examples.

\subsection{Generics and habituals}

In any sentence expressing a generalization, nominal past does not have a past temporal meaning. Rather, it apparently introduces a modal dimension into the interpretation, by allowing variability of reference of the DP. Consider, for example, the contrast between (13a) and (13b):

(13) Generics

a. Wíil-kíi wanaagsani waa ínuu wax bartó boy-defM.past good[+nom] C/F COMP.3MS thing learn.pres.dep 'A (lit. the) good boy must learn something' (deontic generalization)

b. Wíil-ku / wíil-ka wanaagsani waa ínuu wax boy-defM[+nom] / boy-defM good[+nom] C/F COMP.3MS thing bartó learn.pres.dep

'The boy /the good boy must learn something (now)'

(13a) expresses a normative statement, or a lawlike generalization (ideally, a good boy must learn something according to some set of rules). There need not be boys in the context of use: generic quantification is over (deontically) possible individuals, not just the actual ones. Compare with (13b), where the nonpast DP is construed as an episodic subject ('unique boy who must learn something in the actual world') ${ }^{20}$.

\footnotetext{
${ }^{20}$ Note that the nominal past is the only apparent source of genericity in examples such as (13a). The interpreted modality is not associated with any lexical item in the structure: the waa in construction (cf. the English
} 
Similarly, past DPs are required in habitual sentences, involving states or processes that are typically regularly repeated ${ }^{21}$.

(14) Habituals

a. Aróor-tíi wáxaan toosaa líx-da

morning-defF.past expl.F/C.1S wake-up.pres.gen six-defF

'In the morning I wake up at six'

b. Góor walba dúmar-kíi baa áwr-ta fura oo time each women-defM.past F/C camels-defF unload.pres.gen.restr. and aqallá-díi dhisa huts-defF.past build.pres.gen.restr.

'Always the women unload the camels and build the huts'

Habitual sentences are a special case of generalization: over parts of worlds or situations (Kratzer, 1989; Carlson, 1995). Sentence (14a) can be paraphrased most naturally as 'in general, if there is a morning situation, I wake up at six in that situation'. The temporal noun aroórtii 'the morning' is not used to denote a particular time interval here. Likewise, in (14b), where the sentence quantifies over typical situations of the nomadic life in Northern Somalia (the women unload the camels and build the aqal while the men take the stock to water), the past DPs need not be interpreted with the collective subject referring to specific groups of women. The sentence is not necessarily a generalization over instance of observed events: it can be reported in a book. The past DPs are not anaphoric to any antecedent explicitly present in the preceeding speech or text, and they are not 'discourse anaphoric' either. Here, past indicates that we are talking about non-actual, non-episodic individuals.

A similar effect is observed in 'inherent' generics, those describing events that do not require instanciation, as in (15). On the attributive interpretation, 'the winner' in (15a) is relativized to the world of evaluation (i.e., 'whoever is the winner in w'). Past DPs are also required in sentences that express statistical correlations, percentages, prices per kilo, etc., as $(15 b, c)$. Here, the distributive interpretations can be reinforced by adding the quantifier $-b a$ 'each', as in (15c).

\section{(15) 'Inherent' generics}

a. Sánnad kasta qóf-kíi gúuleystaa wúxuu léeyahay year each person-defM.past win.gen.[+nom] expl.F/C.3MS has.pres

kún shillin

thousand shilling

'Every year, the winner (lit. 'the winning person') will receive 1000 shillings'

b. Shír-kaas oo sánnad-kíi már la qabto

conference-defM.dem and year-defM.past time one holds.dep.pres.gen

That conference that is held once a year (= annual conference)

\footnotetext{
'is to' or 'has to' constructions) is formally a verbless sentence, where the root complementizer waa is a pure, non verbal copula and the ín-clause a complement CP (see Lecarme, 1999a, 286-287).

${ }^{21}$ As in English, only stative verbs in Somali have a non-habitual interpretation in the present tense, hence the examples in (14-15) are unambiguously generic/habitual.
} 
c. Kani waa diiqád sahlan oo kú dhacda ilaa sidéed hooyo m.dem.[+nom] F/C depression mild and to happens up.to eight mother tóban-kíi-ba ten-defM.past-each

'This is a mild form of depression that occurs in up to eight out of ten mothers'

The phenomenon is quite general: similar generalization can be made in most languages about definite and demonstrative descriptions that take narrow scope under quantifiers (e.g., 'The elegant man does not wear jewelry'). But if the quantificational variability effect is due to the relation between a generic quantifier and the iota definite description operator, as it is generally assumed, why should the DP be past?

I propose that all these readings combine a quantificational dimension and a modal dimension. The quantificational dimension of the DP comes from a covert generic operator, as it is generally assumed after Lewis (1975) and Heim (1982). The modal dimension comes from the past dissociative morphology: the quantifier does not quantify over actual individuals, but over possible, non-actual ones. In other words, the -ii morphology is not a quantifier, but a modal determiner ${ }^{22}$.

\subsection{Attitude verbs}

In episodic sentences, DPs occuring as objects of attitude verbs expressing 'ignorance' or 'uncertainty' on the part of the speaker (or attitude holder) are marked as past. The sentences (16a,b) have a 'subjective' epistemic reading (cf. Lyons, 1977; Papafragou, 2006) in the sense that they are interpreted as relative to a speaker (or attitude holder)'s knowledge state at the time of utterance:

a. Jawaáb-tíi garán maayo answer-defF.past know Neg.have.pres

'I do not know the answer'

b. Wíx-íi dheeráad ah Állaa óg! thing-defM.past beyond is God.F/C knows.pres.restr.

'(Only) God knows what(ever) lies beyond!'

In (16a), nominal past explicitly marks an epistemic possibility: the modal base consists of worlds which, for all the speaker knows at the time of her utterance, could be the actual world - a conjunction of propositions (e.g., 'the answer is yes' and 'the answer is no') both of which could be true without contradiction, given the speaker's present state of knowledge. The construction can be paraphrased with an ever-free relative, as in (16b).

The overall generalization is that in Somali, definite descriptions can scopally interact with generic operators and propositional attitude verbs. Definite description that take narrow scope in relation to these operators are overtly 'dissociated' from the actual world: the source for the modality can be attributed to the same linguistic device in both cases. Past DPs in either their 'variation' or 'ignorance' readings are closely related to the free relative examples that I will now discuss.

\footnotetext{
${ }^{22}$ This supports the view that generic sentences are implicitly modalized (Heim, 1982; Diesing, 1992). See Heim and Kratzer (1998, 165-170) for a related discussion.
} 


\subsection{Free relatives}

There is no (uninterpretable) $w h$-like element in Somali ${ }^{23}$. The variable element in plain free relatives ('I read what you wrote') is spelled out as qóf 'person' and wáx 'thing'. Plain free relatives, then, are formally relative clauses headed by wáx- $a$ 'the thing', qóf-ka 'the person', etc. The modal dimension of a relative clause correlates with the presence of the -ii morphology. The following examples have the universal or the free choice readings of English -ever free relatives:

a. Qóf-kíi ilá kulma-ba wáx aanán aháyn buu i person-defM.past 1S.with meet-each thing 1S.neg be.inf C/F.3MS 1S moodaa think.pres.gen

'Whoever meets me thinks too highly of me' $\neq$ The specific person $(=q o ́ f-k a)$ who meets me now

b. Wíx-íi aad heysáan ií keena thing-defM.past $2 \mathrm{P}$ have.2p 1S.to bring. $2 \mathrm{p}$ 'Bring me whatever you have' $\neq$ Bring me the specific thing (=wáx-a) that you have now

c. Wíx-íi wár ah ee aad na siisíd wáxaa la isticmáali thing-defM.past new be and $2 \mathrm{~S} 1 \mathrm{~S}$ give.dep.pres expl.F/C one use.inf doonaa

will

'We will use whatever information you send us'

d. Kíi/ búug-gíi aad rabtíd qaadó!

defM.past/book-defM.past 2S want.2s take.imp.2s

'Take whatever/whatever book you want!'

In every one of these examples, the denotation of the free relative covaries with the situation: the identity of the person who meets me differs in each situation, or different things or books are picked up in different possible continuations of the situation (the quantificational meaning can be reinforced by the polarity sensitive item - $b a$ 'each'). As in the cases discussed before, the suffix - $i i$ contributes an additional modal dimension, signaling that the individual is not instantiated in the speaker's actual world.

Somali when-clauses also take the form of a relative clause introduced by a definite head noun meaning 'the moment', 'the time', etc. The presence of -íi correlates with the quantificational reading of the adverbial clause.

(18) When-clauses

a. Már-ka la burburiyó Taleban,...

time-defM one destroy.dep.pres Taleban

'When (lit. the time) the Taleban will collapse,...'

\footnotetext{
${ }^{23}$ The Somali counterpart of English interrogative complements headed by who, what, when, where, how... are relative clauses headed by qóf-ka, cíd-da 'the person', wáx-a 'the thing', sí-da 'the manner', etc. The interpretable interrogative element -ée (e.g. nínk-ée 'which man'?) is not used in complement clauses or free relatives of any kind. See Lecarme (1999a) for a more detailed discussion.
} 
b. Már-kíi la gaboobó wax badán wáa la

time-defM.past one becomes-old.dep.pres thing many $\mathrm{F} / \mathrm{C}$ one

illoobaa

forgets.pres.gen

'When (lit. the time) one gets old one forgets many things'

In (18a), 'the time' when the Taleban will collapse is a specific referential time, and even if this time is a future time, this time belongs to our world. In contrast, no specific referential time is available in the reading of $(18 \mathrm{~b})$, where the past tense morphology is interpreted not along a temporal but along a modal dimension.

Conditionals are modal in nature, in that they involve quantification over possible worlds/situations (Kratzer 1981, 1991 a. o.). In Somali, all types of conditional clauses are modalized free relatives headed by the past DP hád-díi 'the time'-interestingly, the present tense form hád-da means 'now' (lit. the (present) moment').

(19) If-clauses

a. Nin hád-díi uu seexdó oo sóo

man[+nom] time-defF.past 3MS sleeps.dep.pres. and dir.

toosó, waa isá-gíi ún

wakes-up.dep.pres. F/C him-defM.past only

'If (lit. the time) a man goes to sleep and then wakes up, he is only himself' (i.e. the same as he was before) (Proverb)

b. Hád-díi aad rabtó na ráac!

time-defF.past $2 \mathrm{~S}$ want.2s.pre.dep $1 \mathrm{P}$ follow.imp

'Come along with us, if (lit. the time) you want!'

What, then, is the role of the -ii morphology? I suggest that even if the conditional is based on the actual world, the time of the conditional realization (i.e., the denotation of the free relative) is not in the world according to the speaker.

It will be useful at this point to make explicit what analysis I have in mind for free relatives in Somali, and free relatives more generally. I am assuming here a now familiar analysis of free relatives along the lines of Iatridou et al. (2001, 224-225), namely that the nominal expression generated as non-specific (more specifically, as a N-head) is merged as a Spec of CP, possibly after extraction from within the VP (e.g., wáx [C [aad heysáan $\mathrm{t}]]=(17 \mathrm{~b})$ ) and then projects a DP headed by wáx (the Somali complementizer of relative clauses is a phonologically non overt form). I propose that the definite determiner is further decomposable, and one of its constituents, the past tense morpheme, is interpreted not along a temporal but along a modal dimension. This account seems compatible with recent treatments of conditional clauses as free relatives of possible worlds (Schlenker, 2004; Bhatt and Pancheva, 2006).

\subsection{Interim discussion}

In the voluminous literature on English free relatives with -ever, it is widely assumed that free relatives are definite descriptions. The status of the morpheme -ever is more controversial. According to Larson's (1987) analysis, -ever is a universal quantifier. Dayal 
(1997) argues that whatever-phrases have a modal dimension: in the speaker's 'ignorance' reading, whatever-clauses quantify over epistemic alternatives that differ from the actual world only in the identity of the free relative referent (see also Iatridou and Varlokosta, 1997). According to von Fintel's (2000) unified analysis, the content of -ever is presuppositional: -ever introduces a presupposition of variation over the denotation of the free relative (a definite expression) across possible worlds. This variation is construed either as 'indifference' ('I grabbed whatever tool was handy') or 'ignorance' ('There is a lot of garlic in whatever (it is that) Arlo is cooking'), depending on the (counterfactual or epistemic) modal base. But whatever the analysis, a question remains: if the denotation of a definite description varies as a function of the values introduced by a higher quantifier, why do we also need -ever?

My proposals come closer to Dayal's conception of i(dentity)-alternatives as differing from each other only in the denotation of the free relative. From the perspective of the present discussion, what is reflected in the meaning of -ever, like the meaning of - $i i$, is the core meaning of exclusion/dissociation. On this view, the modal properties of English every, who/what/when-ever and French quiconque, quelconque), are related to the temporal polarity items ever and onque of Old English (aefr ylc 'ever each') ${ }^{24}$ and Old French (qui c'onques, que c'onques > quiconque, quelconque). These morphologies should also be viewed synchronically as polar items bound by temporal or modal operators-not the time or world variable itself, but a linguistic sign of exclusion/dissociation.

\section{Evidentiality}

Evidentiality is generally defined as the linguistic encoding of a speaker's source of information, such as perception, report, or inference (Chafe and Nichols, 1986). Evidential markers found in many languages are the linguistic means to indicate these sources. According to Willett's (1988) typology, a true evidential system is fundamentally concerned with the distinction between DIRECT (i.e., perceptual) and INDIRECT (i.e., inferential and reportative) evidence types. Systematic interactions exist crosslinguistically between evidentiality and tense, in that the present tense is interpreted as being based on direct evidence. To the extent that there is a close (causal) connection between one's source of information and one's knowledge, there is also a close relation between evidentiality and epistemic modality. For instance, epistemic modals like must are often the carriers of indirect (inferential) evidence (Palmer, 1986). Still, the problem of how exactly to capture the evidential meaning in the possible worlds semantics assumed for epistemic modality remains open.

In earlier work (Lecarme, 2003), I argued that the study of systems where nominal expressions encode evidential distinctions is obviously relevant to our theoretical understanding of evidentiality, and the nature of the tense/evidential connection. Across languages, DIRECT (basically: visual) evidentiality appears to be the only kind of evidentiality found in nominals. In many (European) languages, the basic distinction visible/invisible is implicitly expressed by the deictic uses of the definite articles, or the system of spatially deictic demonstratives. In other languages, the visible/invisible distinc-

\footnotetext{
${ }^{24}$ See Postma and Rooryck (1996).
} 
tion is superimposed on a proximal-distal system. In languages where determiners also encode temporal distinctions, visibility is associated with the present tense, non-visibility with the past tense $\mathrm{e}^{25}$. I proposed that the classical approaches to evidentiality can be extended to nominals, a domain paradoxically ignored in discussions of evidentiality. I want now to make this proposal more precise.

\subsection{Visual evidentiality}

In Somali, an evidential past must be used in all the contexts where the referent is not observable in principle, such as (20a). Here, past tense signals that the pen is not in the speaker's visual field at the time of utterance. The non-past - $g u$ is unacceptable, contradictory-sounding, hence ungrammatical in such examples. Intuitively, the utterance with - $g u$ is incompatible with its 'inner negation': this is because the semantics of visual perception comes with the normal use of the present tense, as shown in (20b).

\section{(20) Speaker-oriented visibility / invisibility}

a. Qálinkáygii/*-gu méeyey? (—Khaanád-da pen.m.Poss1S-defM.past/*-defM.[+nom] Q.is.ms (-Drawer-defF buu kú jiraa.)

C/F.3MS in stay.pres.gen)

'Where is my pen?' (-In the drawer.)

b. Qálinkáy-gu wáa kee? (—Waa kán gudúudan.) pen.m.Poss1S-defM.[+nom] F/C m.Q (-C/F m.dem red)

'Which one is my pen?' (-The red one.)

In the context of use, the speaker actually knows that her pen is somehow 'present' (e.g., on or under her desk), but in using the -ii morphology, she also adds some crucial piece of information: that she lacks visual experience. In other words, the evidential past provides a negative information, which makes the utterance compatible with the speaker's current evidence.

In Somali as in other languages (e.g., the languages of the Salishan family), a past of evidentiality is characteristically used when talking about a hidden referent. This referent can be close in proximity, as in (21a). In this context, both the speaker and the hearer know that the girl is present in the next room. (21a) is not the simple assertion 'your daughter is pregnant': by using an evidential past, the speaker marks that the girl is absent from the immediate visual context. As a further illustration, a speaker who asserts (21b) presupposes that the hearer knows the students. By using a past evidential, she also signals that the students are not in sight—as evidenced by the hearer's question. The process is not intentional, and not optional either: -ii is unappropriate in both (21a) and (21b) if the girl or the students are visible in the contexts of use.

\section{(21) Talking about invisible referents}

\footnotetext{
${ }^{25}$ See Lecarme (2003) and references cited there. For a more detailed, crosslinguistic investigation of nominal evidentiality, see Imai (2003).
} 
a. Inántaa-dii úur bay leedahay

girl-f.Poss2S-defF.past[+nom] pregnancy C/F.3FS has.3fs

'(Doctor to Mother) Your daughter is pregnant'.

b. Ardaý-dii way jóogayaan. -Kuwée?

students-defF.past[+nom]t C/F.3P stay.prog (-defM.pl.Q)

'(Secretary to Dean) The students are waiting. - Which students?'

Could the - $i i$ morphology be analyzed as anaphorically dependent on a previous 'discourse' context where the referent of the DP was in sight? As discussed in Lecarme (2003), this is not a necessary condition: speakers can use an evidential past to refer to individuals, things or places that were not previously in sight nor in the common ground before the time of utterance. The fact that evidential past sometimes may be used to talk about the future suggests that we are dealing here with modal, not temporal, exclusion:

\section{(22) Talking about the near future}

a. Bal wíil-kíi baan gáarayaa, nabadgélyo!

Well boy-defM.past C/F.1S reach.prog.pres goodbye

'Well, I am going to the boy, goodbye!'

b. Xáj-kíi baan áadayaa

pilgrimage-defM.past C/F.1S go-to.pres.prog

'I am going on the Pilgrimage'

Somali has no grammatical evidentials at the sentence level. The difference between perceptual, inferred and reported evidence is obtained compositionally via the evidential values of the nominal tenses - an analogous linguisitic means to disclose the speaker's source of information. In (23a), both nominals are marked as past, in concord with the past tense marked on the verb. The interpretation conveyed is that of a reportative evidential: (23a) is not a felicitous utterance if the speaker is on the spot of the accident (the sentence out of context has no evidential interpretation). In (23b), both nominals are in the presenttense form. The evidential meaning conveyed is that of (positive) DIRECT evidence. For example, (23b) can be uttered felicitously on the spot of the accident, where both the truck and the road are in sight. On the other hand, $(23 \mathrm{c})$ illustates the inferential evidential meaning: (23c) is a possible utterance in a context in which the road is 'present', hence visible for the speaker. The interpretation that the rhino is 'invisible' or 'absent' (as glosses commonly indicate) is conveyed by the evidential value of -ii. Thus, both (23a) and (23c) indicate INDIRECT evidence, but differ with respect of the source of evidence: in (23c), the evidence is based on observable results (for example, one might infer that the rhino has crossed the road from seeing traces on the ground). Here, the inference is constructed compositionally from the (positive) DIRECT evidential value of the present tense (i.e., the perceptual meaning).

\section{(23) Evidential constructions}

a. Baabúur-kii jíd-kíi buu ká tallaabey

truck-defM.past[+nom] road-defM.past C/F.3MS by pass.past

'The truck crossed the road'

Indirect evidence: report 
b. Baabúur-ku jíd-ka buu ká tallaabey

truck-defM[+nom] road-defM[-nom] C/F.3MS by pass.past

'The truck (visible) crossed the road (visible)'

Direct evidence

c. Wiyíi-shii jíd-ka bay ká tallaabtay

rhinoceros-defF.past[+nom] road-defM C/F.3FS by pass.f.past

'The rhinoceros (invisible) crossed the road (visible)'

Indirect evidence: inference

It appears, then, that past/non-past morphologies have uses that are clearly evidential. The question we must now ask is what 'past' and 'invisible' interpretations have in common. An answer I have offered in previous work is that they must share some feature: exclusion/dissociation. In this section, I will address more precisely the following questions: what are the factors determining the evidential reading of a past nominal? What gives rise to the visual character of nominal evidentiality? How can the visual meaning be incorporated into the semantics of evidentiality?

\subsection{Approaches to (sentential) evidentiality}

There is crosslinguistic evidence that modals and evidentials occupy adjacent segments on the same hierarchy (Oswalt, 1986; Willett, 1988). From an extensive investigation of adverb placement in a number of languages, Cinque (1999) postulates a universal hierarchy of functional projections, in which evidentiality is included as a type of mood.

(24) Cinque's (1999) functional hierarchy Speech Act MoodP $>$ Evaluative MoodP $>$ Evidential MoodP $>$ Epistemic MoodP $>$ Tense

According to Faller's (2002) analysis, evidentiality is the linguistic encoding of the speaker's grounds for making a speech act-in the case of assertion: the speaker's source of information. Quechua evidential enclitics are illocutionary modifiers which add or modify the sincerity conditions of the act they apply to (for instance, the direct evidential $-m i$ adds a sincerity condition which requires that the speaker has the best possible grounds for believing the asserted proposition). In other words, the meaning of the whole expression is not based on truth-values. But as Faller points out, then we should have to distinguish between 'pure evidentials', an illocutionary phenomenon, and other means languages have to express the same distinctions ${ }^{26}$. Another problem is that under this analysis, evidentiality is conceived of as part of the theory of action, not knowledge. There is, then, little hope that we will find principles of general interest about how linguistic knowledge is made compatible with knowledge involved in vision, and how linguistic and non-linguistic (e.g., visual) representations interact in the construction of evidential meanings.

\footnotetext{
26 'The framework of speech act theory might also prove to be the right one in analyzing evidentials in other languages, although not necessarily evidentiality in general. It is a reasonable hypothesis that evidentiality that is encoded by markers of tense and modality can more fruitfully be analyzed within a framework such as possible world semantics, which was developed to account for these categories' (Faller, 2002, 264).
} 
The modal approach which uses a possible world semantics in the analysis of epistemic modality seems more promising. From a semantic point of view, evidential markers do not contribute to the informative proposition, but disclose the source of information. In Izvorski's terms,

'the two dimensions... are logically independent. Yet, natural language typically treats propositions based on perceptual evidence on the part of the speaker as propositions asserted by the speaker to be true' $(1997,3)$.

Kratzer's theory of 'doubly relative' modality is a profound insight into the nature of evidentiality. As in standard analysis in formal semantics, her theory posits an abstract common logical structure unifying the epistemic and root uses of modals. The lexical semantics of the modal encodes a quantificational force ( $\square$ or $\diamond$, a relation between sets of worlds). A covert variable next to the modal picks up a contextually salient set of worlds as a restrictor, and this contextually salient set determines how the modal is interpreted. On this view, epistemic accessibility is defined as compatibility relative to a knowledge state: (25) will be true in a world $w$ if and only if it follows from 'what is known in w' that John is at home. Speakers do not claim that $p$ (='John is at home') is true, but that a certain logical relation holds between $p$ and what they know.

\section{(25) (in view of what is known) John must be at home}

In Kratzer's theory, the quantificational part of a modal (the modal relation) is defined along two 'conversational backgrounds': the modal base and the ordering source, both functions from worlds to propositions ${ }^{27}$. An epistemic modal base ('what we know') determines the set of worlds which are epistemically accessible from w. The innovation in Kratzer's theory is the ordering source, an additional construct for ordering worlds with respect to a reference world. The ordering source ( $w$ is at least as close to the ideal as w') imposes an order on the modal base and let the quantification range only over the closest worlds in the modal base. Thus, if the ordering source for the modal in (25) is the set of propositions which represent 'the normal course of events', the 'most normal world' may be a world in which John is not at home.

This view has crucial consequences on our undertanding of evidentiality. Epistemic modal bases take ordering sources related to information. As Kratzer suggests, in uttering (25), speakers convey that they do not rely on known facts alone. They use other sources of information which are more or less reliable. These other sources potentially include extralinguistic information. This opens the possibility that evidential meanings depend on the kind of ordering source supplied by the context.

Izvorski (1997) proposed a formal analysis of indirect evidentiality in this framework ${ }^{28}$. Her arguments are based on the analysis of the 'perfect of evidentiality' in Bulgarian, Turkish and other languages. As (26a) shows, a present perfect morphology in

\footnotetext{
${ }^{27}$ Kratzer $(1981,1991)$ does not explain how a 'conversational background' is formally selected from the context of the utterance, but she does suggest that the distinction between modals with epistemic and circumstantial modal bases may correlate with a difference in argument structure. As many have previously noted, there are good arguments that modals with a circumstantial modal base (i.e., root modals) have an implicit agent argument which can act as a syntactic controller, whereas epistemic modals are structurally speaker oriented.

${ }^{28}$ See also Garrett's (2002) analysis of the Tibetan indirect evidential.
} 
Bulgarian is interpreted not as a present perfect, but as a perfect of evidentiality (glossed as PE). The indirect evidential reading is linked to the present tense: this reading is unavailable in non-finite environments, as well as in the formation of the past and future perfects (26b).

a. Ivan izpil vsičkoto vino včera

Ivan drunk.PE all.the wine yesterday

Ivan apparently drank all the wine yesterday (evidential reading)

b. Ivan trjabvada e izpil vsičkoto vino včera

Ivan must is drunk all.the wine yesterday

Ivan must have drunk all the wine yesterday (perfect reading)

According to Izvorski's analysis, indirect evidentials (PE or apparently) are semantically propositional operators. Sentences of the form EVp are represented in (27): the EV-operator is an universal epistemic modal with a presupposition of available indirect evidence for the truth of the proposition it modifies. This presupposition restricts the domain of quantification of $\mathrm{EV}$, for a given world, to the set of propositions which constitute the available indirect evidence in that world (e.g., 'There are empty bottles in Ivan's office' or 'Mary said that $p$ '). The domain of quantification is further restricted by a stereotypical ordering source (e.g., 'If there are empty bottles in someone's office, that person has drunk the wine' or 'Normally, Mary is a reliable source of information').

a. Assertion: $\square p$ in view of the speaker's knowledge state

b. Presupposition: Speaker has indirect evidence for $p$

In addition, Izvorski is able to derive the presupposition of available indirect evidence from the exclusion/dissociation formalism, thereby defining the formal link between the perfect of evidentiality and the present perfect. For the Present perfect, the compositional meaning is that the consequent state of a past eventuality holds at the time of utterance. For the perfect of evidentiality, the compositional meaning is that the worlds in which $p$ is known are epistemically inaccessible from $w_{\mathrm{s}}$, le world of the speaker; the speaker has therefore no direct evidence for $p$ (the modal contribution of the perfect aspect morphology). The accessible worlds are those in which $p$ ' (= 'there are consequences or results of $p^{\prime}$ ) is true (the modal contribution of the present tense). Together with a stereotypical ordering source, this compositional meaning derives the inference and report interpretations. On this view, evidentiality is a kind of epistemic modality: the presupposition of indirect evidence contributes a proposition $p$ ' to the modal base, which serves to restrict the domain of the evidential operator ${ }^{29}$. In Izvorski's terms,

'...it is more useful to think of the terms DIRECT and INDIRECT... as making a distinction based not on whether or not the evidence is perceptual, but on whether or not the evidence justifies the speaker's belief in a proposition' (1997, 3-4).

\footnotetext{
${ }^{29}$ This analysis is similar to Kratzer's treatment of (modal) conditionals: for each world, the if-clause is added to the set of propositions the modal base assigns to that world, thus restricting the accessibility relation.
} 
Still, there is a nontrivial, linguistic difference between classical inference on the one hand, and the evidentially modalized counterpart of it. Whether or not the evidence is perceptual does matter: when a speaker utters an evidential statement, the grounds upon which her knowledge is claimed to rest is something more restricted and more specific than the proposition 'there are consequences or results of $p$ ': crucially, some internal structure corresponds to DIRECT, perceptual experience. Even if the inference is not valid (i.e., if Ivan has not drunk the wine), the particular epistemic state that the speaker is in still includes some perceptual knowledge. Assuming that evidentiality is part of the presuppositional content does not capture that fact.

Here, I argue that the treatment of direct evidentiality in possible world semantics is indeed possible, provided that we reinterpret Kratzer's doubly relative semantics. Informally, we might assume an ordering source that singles out the accessible worlds which come closest to an ideal in which the speaker has direct (visual) evidence: a perceptual ordering source, which relates informal access (e.g. seeing) to current knowledge.

\subsection{Extending Kratzer's theory}

There are two necessary factors in the computation of the (either sentential or nominal) evidential meanings. First, evidential expressions must be anchored to the utterance time. At any time, the evidence available to speakers is made compatible with a set of worlds which, for all they know, is the actual world. Deictic anchoring to the present tense is the crucial factor: as discussed earlier (section 2.2), the evidential interpretation of past DPs is unavailable in generic and generalizing sentences, where the present tense temporally locates the generic predicate, not the core eventuality. Second, evidentiality has a perceptual component. When uttering an evidential statement, a speaker also claims that her knowledge rests on perceptual grounds. This kind of inference crucially differs from inference from reasoning in that it derives from experience, not a mental construct.

Nominals open up a refreshing new way of looking at the phenomenon. As noted earlier, the kind of evidentiality found in nominals is typically DIRECT. At the same time, we can observe a clear correlation between tense and direct (i.e., visual) evidentiality, which is generally not found at the sentence level. Let us consider again the Somali examples where the invisible referent is actually present at the time of utterance. In the context of $(28 \mathrm{a}=21 \mathrm{a})$, both interlocutors actually 'know' that the girl is present in the next room. The referent of the DP is epistemically 'present', but evidentially 'past', that is, invisible to the speaker (compare with (28b), which is a felicitous utterance if and only if the referent is in sight $)^{30}$ :
(28)
a. Inántáa-dii
úur bay leedahay
girl.f.Poss2S-defF.past.[+nom] pregnancy C/F.3FS has.3fs
(Doctor to Mother): - Your daughter (invisible) is pregnant.
b. Ínan-ka yar ú yeer!
boy-defM small to call
'Call the little boy! (visible)

${ }^{30}$ See von Tiling's (1919) study for similar examples and contexts, based on the Isaaq dialect of Somali. 
The nominal past here can only be understood as involving a shift in the epistemic context of the speaker. Intuitively, exclusion/dissociation operates in a higher layer of sructure in terms of Cinque's (1999) functional hierarchy (24). Past does not exclude the referent of the DP from 'what is known' by the speaker, but from a more restricted and more specific set, including the domain of individuals perceived by the speaker/viewer at a given moment.

My proposal is therefore, in the spirit of Kratzer, to make explicit the ordering source that the evidential past is sensitive to, and assume that evidential epistemic modality is defined as in (29).

\section{(29) Evidential modality}

Modal relation:

Modal base: epistemic

Ordering source: perceptual (in the most ideal or 'normal' of her worlds, the speaker has DIRECT (visual) evidence.

The modal base is the set of worlds epistemically accessible from the world of the speaker at the time of utterance. Universal quantification takes place over the epistemically accessible worlds that remain after the ordering source has applied to the set of worlds determined by the modal base. As a result, the accessibility relation supplies a 'totally realistic' modal base, that is, the set of propositions that exhaustively describe the perceptual world of the speaker at the time of utterance (e.g., 'this is my pen', 'my pen is red', 'there are empty wine bottles here'...). On this acccount, the 'default' modal force characteristic of evidential statements derives from perception. Evidentiality differs from 'subjective epistemic modality' described above (section 2.3) in that it is a subjective neccessity: if our perceptual system is reliable and works properly, what we perceive directly must be true. Our perception of objects and events around us is veridical, a true representation of what those objects are and where they are situated in space. The analysis correctly predicts that evidential statements, like other modal statements, are contingent: our perceptions can be mistaken. But the perception-based knowledge relevant for evidentiality (a linguistic notion) are facts of our world, not necessary truths.

Now, why is direct evidentiality visual? It cannot be the case that the tenses 'encode' the visual meaning. The visual meaning cannot plausibly be derived from a conversational implicature either, since those implicatures are typically cancellable. The most natural answer is that the hierarchical structure of evidential systems linguistically reflects the epistemic importance of visual perception in human knowledge. This is because visual perception contains an epistemic component (Dretske, 1969, 1990) by which non-linguistic and linguistic representations are mutually compatible ${ }^{31}$. From the speaker/viewer's perspective, the 'visual' meaning can be derived as follows.

(i) What is brought up by the context is not a proposition (because propositions cannot be perceived), but what can be thought of as the complement of a perception

\footnotetext{
${ }^{31}$ Beyond linguistics (Jackendoff, 1983), there is an enormous literature concerning the relation between knowledge and (visual) perception in the related fields of philosophy of perception (Dretske, 1969, 1990) and neuropsychology (Milner and Goodale, 1995).
} 
verb: semantically, an object or an event; syntactically, a DP or a bare infinitiveexpressions like 'my pen' 'bottles in the office', 'John drink the wine', that is, the uppermost level of perceptual processing (i.e., Dretske's 1969 'non-epistemic seeing').

(ii) The meaning of DIRECT perception does not come from a perception verb (as in perceptual reports)—or from an abstract perceptual predicate or operator ${ }^{32}$. The meaning of DIRECT perception comes from the present time, 'now'. We can think of the deictic present tense as some functional equivalent of demonstrative reference, an indexing mechanism that relates informational access to current knowledge. In evidential contexts, deictic present tense indicates DIRECTness ${ }^{33}$.

(iii) Anchoring to the utterance time is responsible for matching linguistic with nonlinguistic representations, yielding perceptual knowledge (propositions like 'the pen is red', 'this is my pen', 'there are bottles in Ivan's office...') (i.e., Dretske's 1969 'primary epistemic seeing').

(iv) Evidential inference crucially rests on perceptual knowledge (i.e., representations in (iii): we come to know that the rhino has crossed the road by seeing traces on the ground, we come to know that Ivan drank the wine by seeing empty bottles in his office, etc. This corresponds to Dretske's 1969 'secondary epistemic seeing', and crucially differs from inference from reasoning.

On this view, we can think of true evidentials, which come with a lexically specified accessibility relation (like attitude verbs), as lexicalizing the ordering source. Assuming a partial ranking of all possible sources gives clues to access the direct (perceptual) meanings and derive the basic distinctions encoded by the evidential systems. The hierarchy of evidential types (DIRECT, INDIRECT INFERENCE, INDIRECT REPORTATIVE) might be thought of in binary terms: (visually) perceived, (visually) perceived resultant state, lack of personal experience (or non-speaker's evidence).

This has only been an outline of how to spell out an analysis of DIRECT evidentiality in a classical, truth-conditional semantics. I hope this beginning has looked promising enough to motivate interest in further investigation of evidentiality in nominals, and what it reveals about the other systems with which language interacts and interfaces.

\section{Conclusions}

What has been the leading thread troughout this paper is the common abstract meaning underlying the different uses of nominal past, namely exclusion/dissociation. The interaction of modality and temporality has a natural parallel in the nominal domain: past

\footnotetext{
${ }^{32}$ On perceptual reports, see Higginbotham (1983a); on the relation between perceptual reports and evidentiality, see Van der Does and Lambalgen (2000).

${ }^{33}$ This is a feature of many languages with grammatical evidentials. According to Faller (2002, 123), the Qechua evidential $m i$ encodes direct evidence. The same evidential value is implicated by simple assertions. From a typological perspective (e.g. De Haan (to appear)), many languages only have overt evidentials for indirect evidence types, and in those cases, zero is interpreted as direct evidence. In languages that make the distinction between visual and nonvisual direct evidence, evidence by seeing is the default evidential.
} 
as referential displacement (distinct from the notion of precedence, or chronological order) makes it possible to talk about possible worlds that stand in a certain relation to the actual world. If Kratzer's theory can be supplemented with a perceptual component, as I proposed, past gives rise to the 'non-actual', 'unknown', 'invisible' modal meanings, depending on different choices of modal bases and ordering sources.

From our study of the Somali determiner system, it appears that demonstratives and evidentials encode two different aspects of visual cognition: past versus nonpast is linked to visual perception, visual and episodic memories, knowledge, and reasoning about abstract entities that cannot be perceived. This is consistent with the distinction between two separate visual systems - one for conscious perception and another for the control of action $^{34}$. We hope in future work to investigate why these particular components of meaning, 'past' and 'invisible', correlate in precisely this way, and what this reveals more generally about the interfaces between linguistic meanings and the visual system. If language can be shown to make use of a more primitive, domain-general exclusion/dissociation feature, it might be the case that the evidential values of past morphemes could be taken as their core meaning ${ }^{35}$. If so, our experience of time may ultimately derive from perceptual mechanisms and processes, which in turn enable us to perceive objects and events.

\section{References}

Anderson, Stephen, Lea Brown, Alice Gaby, and Jacqueline Lecarme. 2006. Life on the edge: There's morphology there after all! In Lingue e Linguaggio, volume 1, pages $1-16$.

Bach, Emmon. 1981. On time, tense, and aspect: An essay in English metaphysics. In Peter Cole (ed.), Radical Pragmatics, pages 62-81. New York: Academic Press.

Bhatt, Rajesh and Roumyana Pancheva. 2006. Conditionals. In Martin Everaert and Henk van Riemsdijk (eds.), The Blackwell Companion to Syntax, volume 1, pages 638-687. Oxford: Blackwell.

Burton, Strang. 1997. Past tense on nouns as death, destruction, and loss. In Kiyomi Kusumoto (ed.), NELS, volume 27. Amherst: University of Massachusetts, GLSA.

Bybee, Joan, Revere Perkins, and William Pagliuca. 1994. The Evolution of Grammar: Tense, aspect and modality in the languages of the world. Chicago: University of Chicago Press.

Carlson, Gregory. 1995. Truth conditions and generic sentences: Two contrasting views. In Gregory Carlson and Francis Jeffry Pelletier (eds.), The Generic Book, pages 224237. Chicago: University of Chicago Press.

\footnotetext{
${ }^{34}$ See Goodale and Milner (1992), Milner and Goodale (1995).

${ }^{35}$ I refer here to the cognitive mechanisms underlying temporality and evidentiality, not the historical evolution of grammatical forms. Diachronically, evidential meanings are often acquired by modal, tense and aspect morphemes (Bybee et al., 1994). Among languages with (sentential) evidentials, visual evidentials typically derive from already grammaticalized tense or aspect morphemes, or demonstratives (see De Haan, 1998, to appear).
} 
Chafe, Wallace and Johanna Nichols (eds.). 1986. Evidentiality: The Linguistic Coding of Epistemology. Norwood, NJ: Ablex Publishing Corporation.

Chomsky, Noam. 1995. The Minimalist Program. Cambridge, Mass.: MIT Press.

Chomsky, Noam. 2000. Minimalist inquiries: The framework. In Roger Martin, David Michaels, and Juan Uriagereka (eds.), Step by Step: Essays on minimalist syntax in honor of Howard Lasnik, pages 89-156. Cambridge, Mass.: MIT Press.

Chomsky, Noam. 2001. Derivation by phase. In Kenstowicz (ed.), Ken Hale: A Life in Language, pages 1-52. Cambridge, Mass.: MIT Press.

Chomsky, Noam. to appear. On phases. In Robert Freidin, Carlos Otero, and Maria-Luisa Zubizarreta (eds.), Foundational issues in linguistic theory. Cambridge, Mass.: MIT Press.

Cinque, Guglielmo. 1999. Adverbs and functional heads: A cross-linguistic perspective. Oxford: Oxford University Press.

Comrie, Bernard. 1985. Tense. Cambridge: Cambridge University Press.

Dayal, Veneeta. 1997. Free relatives and ever: Identity and free choice readings. In Aaron Lawson and Eun Cho (eds.), SALT VII Proceedings, pages 99-116. Ithaca, NY: CLC Publications, Cornell University.

De Haan, Ferdinand. 1998. The category of evidentiality. Manuscript, University of New Mexico.

De Haan, Ferdinand. to appear. Visual evidentiality and its origins. Diachronica.

Diesing, Molly. 1988. Bare plural subjects and the stage/individual contrast. In Manfred Krifka (ed.), Genericity in Natural Language: Proceedings of the 1988 Tübingen Conference, pages 88-42. Tübingen: Seminar für natürlich-sprachliche Systeme.

Diesing, Molly. 1992. Indefinites. Cambridge, Mass.: MIT Press.

Dretske, Fred I. 1969. Seeing and Knowing. Chicago, Ill.: University of Chicago Press.

Dretske, Fred I. 1990. Seeing, believing and knowing. In Daniel N. Osherson, Stephen M. Kosslyn, and John M. Hollerbach (eds.), Visual Cognition and Action: An Invitation to Cognitive Science, volume 2, pages 129-148. Cambridge, Mass.: MIT Press.

Embick, David and Rolf Noyer. 2001. Movement operations after syntax. Linguistic Inquiry, 32(4):555-595.

Enç, Mürvet. 1981. Tense without Scope: An Analysis of Nouns as Indexicals. Ph.D. thesis, University of Wisconsin - Madison.

Enç, Mürvet. 1986. Towards a referential analysis of temporal expressions. Linguistics and Philosophy, 9:405-426. 
Enç, Mürvet. 1991. The semantics of specificity. Linguistic Inquiry, 22(1):1-25.

Faller, Martina. 2002. Semantics and Pragmatics of Evidentials in Cuzco Quechua. Ph.D. thesis, Stanford University, Stanford.

von Fintel, Kay. 2000. Whatever. In Brenda Jackson and Tanya Matthews (eds.), Proceedings from the Conference on Semantics and Linguistics (SALT, volume 10. CLC Publications.

Garrett, Edward. 2002. Evidentiality and Assertion in Tibetan. Ph.D. thesis, UCLA.

Goodale, Melvyn and David Milner. 1992. Separate visual pathways for perception and action. Trends in Neuroscience, 15:20-25.

Heim, Irene. 1982. The Semantics of Definite and Indefinite Noun Phrases. Ph.D. thesis, University of Massachusetts, Amherst.

Heim, Irene and Angelika Kratzer. 1998. Semantics in Generative Grammar. Oxford: Basil Blackwell.

Higginbotham, James. 1983a. The logic of perceptual reports: An extensional alternative to situation semantics. Journal of Philosophy, LXXX:100-127.

Higginbotham, James. 1983b. Logical form, binding, and nominals. Linguistic Inquiry, $14: 395-420$.

Higginbotham, James. 2005. Evidentials: Some preliminary distinctions. Ms. USC.

Hiraiwa, Ken. 2005. Dimensions of Symmetry in Syntax: Agreement and Clausal Architecture. Ph.D. thesis, MIT, Cambridge, Mass.

Iatridou, Sabine. 2000. The grammatical ingredients of counterfactuality. Linguistic Inquiry, 31.2:231-271.

Iatridou, Sabine, Elena Anagnostopoulou, and Roumyana Izvorski. 2001. Some observations about the form and meaning of the perfect. In Michael Kenstowicz (ed.), Ken Hale: A Life in Language, pages 189-238. Cambridge, Mass.: MIT Press.

Iatridou, Sabine and Spyridoula Varlokosta. 1997. Pseudoclefts crosslinguistically. Natural Language Semantics, 6(1):3-28.

Imai, Shingo. 2003. Spatial Deixis. Ph.D. thesis, State University of New York at Buffalo.

Izvorski, Roumyana. 1997. The present perfect as an epistemic modal. In Aaron Lawson and Eun Cho (eds.), SALT VII Proceedings, pages 99-116. Ithaca: CLC Publications.

Jackendoff, Ray. 1983. Semantics and Cognition. Cambridge, Mass.: MIT Press.

Kirk, John W. C. 1905. A Grammar of the Somali Language. Cambridge: Cambridge University Press. 
Klein, Wolfgang. 1994. Time in Language. London: Routledge.

Kratzer, Angelika. 1981. The notional category of modality. In Hans-Jürgen Eikmeyer and Hannes Rieser (eds.), Worlds, words, and contexts, pages 38-74. Berlin: de Gruyter.

Kratzer, Angelika. 1989. An investigation of the lumps of thought. Linguistic and Philosophy, 12:607-653.

Kratzer, Angelika. 1991. Modality. In Arnim von Stechow and Dietrich Wunderlich (eds.), Semantics: An International Handbook of Contemporary Research, pages 639650. Berlin: de Gruyter.

Kratzer, Angelika. 1995. Stage-level and individual-level predicates. In Gregory N. Carlson and Francis Jeffry Pelletier (eds.), The Generic Book. Chicago: University of Chicago Press.

Krifka, Manfred. 1992. Thematic relations as links between nominal reference and temporal constitution. In Ivan Sag and Anna Szabolsci (eds.), Lexical Matters. Stanford: CLSI Publications.

Larson, Richard K. 1987. Missing prepositions and the analysis of English free relative clauses. Linguistic Inquiry, 16:239-266.

Larson, Richard K. and Sungeun Cho. 1999. Temporal adjectives and the structure of possessive DPs. In Sonya Bird, Andrew Carnie, Jason D. Haugen, and Peter Norquest (eds.), WCCFL, volume 18, pages 299-311. Somerville, Mass.: Cascadilla Press.

Larson, Richard K. and Sungeun Cho. 2003. Temporal adjectives and the structure of possessive DPs. Natural Language Semantics, 11:217-247.

Lecarme, Jacqueline. 1996. Tense in the nominal system: the somali DP. In Jacqueline Lecarme, Jean Lowenstamm, and Ur Shlonsky (eds.), Studies in Afroasiatic Grammar. The Hague: Holland Academic Graphic. Papers from the 2nd Conference on Afroasiatic Languages, Sophia Antipolis 1994.

Lecarme, Jacqueline. 1999a. Focus in somali. In Georges Rebuschi and Laurie Tuller (eds.), The Grammar of Focus, pages 275-309. Amsterdam: John Benjamins.

Lecarme, Jacqueline. 1999b. Nominal tense and tense theory. In Francis Corblin, Carmen Dobrovie-Sorin, and Jean-Marie Marandin (eds.), Empirical Issues in Formal Syntax and Semantics, volume 2, pages 332-354. The Hague: Holland Academic Graphics. Selected Papers from the Colloque de Syntaxe et Sémantique à Paris (CSSP).

Lecarme, Jacqueline. 2002. Gender 'polarity': Theoretical aspects of somali nominal morphology. In Paul Boucher (ed.), Many Morphologies, pages 109-141. Somerville, Mass.: Cascadilla Press. 
Lecarme, Jacqueline. 2003. Nominal tense and evidentiality. In Jacqueline Guéron and Liliane Tasmowski (eds.), Tense and Point of View. Presses de l'Université Paris XNanterre.

Lecarme, Jacqueline. 2004. Tense in nominals. In Jacqueline Guéron and Jacqueline Lecarme (eds.), The Syntax of Time, pages 441-475. Cambridge, Mass.: MIT Press.

Lewis, David. 1975. Adverbs of quantification. In Edward Keenan (ed.), Formal Semantics in Natural Language, pages 3-15. Cambridge: Cambridge University Press.

Lyons, John. 1977. Semantics, volume 1 and 2. Cambridge: Cambridge University Press.

Milner, David and Melvyn A. Goodale. 1995. The Visual Brain in Action, volume 27 of Oxford Psychology Series. Oxford: Oxford University Press.

Musan, Renate. 1995. On the temporal interpretation of noun phrases. Ph.D. thesis, MIT, Cambridge, Mass.

Musan, Renate. 1997. Tense, predicates, and lifetime effects. Natural Language Semantic, 5:271-301.

Nordlinger, Rachel and Louisa Sadler. 2004. Nominal tense in a crosslinguistic perspective. Language, 80(4):776-806.

Oswalt, Robert L. 1986. The evidential system of Kashaya. In Wallace Chafe and Johanna Nichols (eds.), Evidentiality: The Linguistic Coding of Epistemology, volume 20 of Advances in Discourse Processes, pages 29-45. Norwood, New Jersey: Ablex Publishing Corporation.

Palmer, Franck R. 1986. Mood and Modality. Cambridge: Cambridge University Press.

Papafragou, Anna. 2006. Epistemic modality and truth conditions. Lingua, 116:16881702.

Partee, Barbara. 1983. Genitives - a case study. published as an appendix to Theo Jansen, Compositionality. In Johan van Benthem and Alice ter Meulen (eds.), Handbook of Logic and Language, pages 464-470. Cambridge, Mass.: MIT Press. Also published by North Holland, Amsterdam.

Partee, Barbara. 2000. Some remarks on linguistic uses of the notion 'event'. In Carol Tenny and James Pustejowsky (eds.), Events as Grammatical Objects, pages 483-495. Stanford: CLSI Publications.

Pesetsky, David and Esther Torrego. 2001. T-to-C: Causes and consequences. In Michael Kenstowicz (ed.), Ken Hale: A Life in Language, pages 355-426. Cambridge, Mass.: MIT Press.

Postma, Gertjan and Johann Rooryck. 1996. Modality and Possession in NPs. In Kiyomi Kusumoto (ed.), Proceedings of NELS, volume 26, pages 87-100. Cambridge, Mass.: Harvard University and MIT. 
Roehrs, Dorian. 2006. The morpho-syntax of the Germanic Noun Phrase: Determiners move into the Determiner Phrase. Ph.D. thesis, Indiana University, Bloomington, Indiana.

Schlenker, Philippe. 2004. Conditionals as definite descriptions (a referential analysis). In Ruth Kempson and Klaus von Heusinger (eds.), Research on Language and Computation, volume 2, pages 417-462. Special issue on 'Choice Functions in Semantics'.

von Stechow, Arnim. 2002. Temporal prepositional phrases with quantifiers—-some additions to Pratt and Francez (2001). Linguistics and Philosophy, 25(5-6):755-800.

von Tiling, Rainer Maria. 1919. Die Vokale des bestimmten Artikels im Somali. Zeitschrift für Kolonialsprachen, 9(3):132-166.

Tonhauser, Judith. 2006. The temporal semantics of noun phrases: Evidence from Guaraní. Ph.D. thesis, Stanford University, Stanford.

Van der Does, Jaap and Michiel Van Lambalgen. 2000. A logic of vision. Linguistics and Philosophy, 23(1):1-92.

Willett, Thomas. 1988. A cross-linguistics survey of the grammaticalization of evidentiality. Studies in Language, 12:51-97.

\section{Notes}

${ }^{1}$ This chapter develops ideas outlined in Lecarme (2003), and is based on material presented at the DIP Colloquium (University of Amsterdam, October 2003), the 27th GLOW Colloquium (Aristotle University of Thessaloniki, April 2004) and the International Round Table on Tense, Aspect and Modality (Universités Paris 7 and Paris 3, December 2005). I wish to thank the participants at those events. I am particularly indebted to Jacqueline Guéron for valuable written comments on an earlier version, and to Bascir Kenadid (Bashiir Nuur Keenadiid) for insightful discussion of the Somali data.

${ }^{2}$ See Lecarme (1996, 1999b, 2003, 2004). 'Nominal tense' is a well attested morphological phenomenon (see Nordlinger and Sadler (2004) for typological investigation from a wide-ranging survey of languages where the phenomenon occurs). Further elaboration depends on a fine-grained syntactic analysis of the relevant structures and the sentences in which they occur. If the 'temporal markers' in some languages are actually nominal aspect, not nominal tense, as argued by Tonhauser (2006) for Guaraní, then we might expect languages to allow tensed, aspectual, or tenseless nominals, a further parallel with clauses.

${ }^{3}$ In Standard Somali, no indefinite article appears on the surface: a man is expressed with the Somali equivalent of man (the indefinite form can mean either non-specific or specific indefinite).

${ }^{4}$ In Lecarme $(1996,1999 \mathrm{~b})$, the suffixed definite forms are derived by syntactic N-to-D movement. A morphological merger analysis of the sort developed by Embick and Noyer (2001) would rather treat these cases as involving Lowering the entire $\mathrm{D}$, which is internally complex, to the head of its NP complement, leading to a parallel morphological structure root- $\phi$-tense for both the tensed nominal and verbal forms. See Lecarme (2004, 343-344) for more details.

${ }^{5}$ This distributional fact is generally not mentioned in the literature (but see Kirk (1905) for a thorough description, based on the Isaaq dialect of Somali). Since the relevant DPs can occur in non-subject position, the past ending is not to be assimilated to the $-i$ nominative morphology which is marked at the right edge of the phrase under certain conditions (see Anderson et al. (2006) for a recent analysis). Assuming that Somali $\mathrm{D}$ is $\varnothing$ with gender agreement and tense incorporated to $\mathrm{D}$ (T-to-D), the relative order of the possessive and demonstrative enclitics suggests that demonstratives are merged higher than Spec,TP (presumably, Spec,DP). A full account of how this hierarchical structure is linearized is beyond the scope of this article. 
${ }^{6}$ Narrow syntax is taken here as the core recursive aspect of the language faculty (Chomsky, 1995, and subsequent work).

${ }^{7}$ The examples in the article follow the national orthography with small modifications: the main tonal accent of a prosodic word is noted with an acute accent; hyphens are added for morpheme separation. Key to Somali gloss: $\mathrm{C} / \mathrm{F}=$ complementizer/'focus marker' (I analyze the baa/waa morpheme as a declarative root complementizer); defF/M = definite feminine / masculine article, dem = demonstrative, dep. = dependent, dir. $=$ directional particle, expl $=$ expletive, gen $=$ general/generic, Poss $=$ possessive, prog. $=$ progressive, neg. $=$ negation, restr. = restrictive agreement. Pronominal clitics are identified by their person, gender, and number features (upper cases). Referential third object pronouns are $\varnothing$ in Somali. Low cases $=$ agreement features. Most examples in the text are from my previous papers, from Shabeelnaagood (a Somali play by Hassan Sheikh Mumin), from the BBC Somali Service, and from Google.

${ }^{8}$ I envisage a parallel treatment of CP and DP, as often implied in the literature (see Hiraiwa, 2005, for a recent syntactic account). On the semantic side, many parallels have been suggested between nominals and clauses: verbs in general are assumed to have neo-Davidsonian meanings, where the VP names a "property of eventualities (events and states, cf. Bach (1981)), not a single event. Events are assumed to have the same logical type as individual entities, that is, $\langle\mathrm{e}\rangle$. 'Sentence determination' is obtained by quantifying over the event variable (Krifka, 1992; Partee, 2000; von Stechow, 2002). Building on these studies, I will assume that noun phrases, like sentences, contain implicit quantification over times, and implicit restrictions to times contained in a contextually salient interval.

${ }^{9}$ The functional head $\mathrm{n} *$ is labelled Appl(icative) in Lecarme (2004).

In the following, I will use 'tense' as 'morphological tense' (possibly null), $\mathrm{T}$ as the syntactic category $\mathrm{T}$ (ense), the locus of computation of tense features ([T]), and PAST as semantic tense (some abstract temporal quantifier).

${ }^{10}$ On the special morpho-syntactic status of nominal number, see Lecarme (2002).

${ }^{11}$ On the syntactic and semantic difference between adjectives (white) and stative verbs (be white), and between inflected adjectives/predicative nouns and (reduced) relative clauses in Somali, see the discussion in Lecarme (2004).

${ }^{12}$ Here and below, I assume that there is no asymmetry between the application of tense to individuals and to events. The individual's 'time of existence' is to be understood as the time associated with underlying existential quantification (making the temporal location of an individual parallel to the temporal location of an event), not the whole time-span of an individual's existence, which is, in case of an animate individuals, their lifetime (Kratzer, 1995; Musan, 1995, 1997).

${ }^{13}$ On the temporal location of the genitive/possessive relation, see Burton (1997), Larson and Cho (1999, 2003).

${ }^{14}$ See note 12 above.

${ }^{15}$ As expected, proper names, kind-denoting DPs (e.g. naasleý-da 'the mammal(s))' and DPs that denote abstract entities (e.g. xisaáb-ta 'the mathematics') do not reflect tense distinctions.

${ }^{16}$ See Musan's $(1995,89-92)$ arguments against a scope approach of the presuppositional vs. cardinal distinction (Diesing, 1988, 1992), namely that presuppositional noun phrases under the scope of a temporal adverb of quantification still can be temporally independent.

${ }^{17}$ In the framework of Chomsky (2001, to appear), a DP with an interpretable tense feature should reach the edge position of the phases $\mathrm{V}^{*} \mathrm{P}$ and $\mathrm{CP}$ (i.e., outer Spec, $\mathrm{v}^{*}$ and Spec, T, if T inherits the edge feature of C) typically associated with 'surface structure' interpretation (specificity, new/old information, topicality, etc.).

${ }^{18}$ See Lecarme $(1996,1999 \mathrm{~b})$ for more examples. The fact that the temporal presupposition is not required to be in the common ground makes it more similar to assertions than a presupposition under a Stalnakerian analysis, although the presupposition is not directly asserted. This, however, is left for future discussion.

${ }^{19}$ Roehrs (2006, on Scandivian) makes the interesting claim that 'specificity' originates in a syntactic position lower than D, and that determiners are parallel to auxiliaries in the clause.

20 Note that the nominal past is the only apparent source of genericity in examples such as (13a). The interpreted modality is not associated with any lexical item in the structure: the waa in construction (cf. the English 'is to' or 'has to' constructions) is formally a verbless sentence, where the root complementizer waa is a pure, non verbal copula and the in-clause a complement CP (see Lecarme, 1999a, 286-287).

${ }^{21}$ As in English, only stative verbs in Somali have a non-habitual interpretation in the present tense, hence the examples in (14-15) are unambiguously generic/habitual.

${ }^{22}$ This supports the view that generic sentences are implicitly modalized (Heim, 1982; Diesing, 1992). See Heim and Kratzer (1998, 165-170) for a related discussion. 
${ }^{23}$ The Somali counterpart of English interrogative complements headed by who, what, when, where, how... are relative clauses headed by qóf-ka, cíd-da 'the person', wáx-a 'the thing', sí-da 'the manner', etc. The interpretable interrogative element -ée (e.g. nínk-ée 'which man'?) is not used in complement clauses or free relatives of any kind. See Lecarme (1999a) for a more detailed discussion.

${ }^{24}$ See Postma and Rooryck (1996).

${ }^{25}$ See Lecarme (2003) and references cited there. For a more detailed, crosslinguistic investigation of nominal evidentiality, see Imai (2003)

${ }^{26}$ 'The framework of speech act theory might also prove to be the right one in analyzing evidentials in other languages, although not necessarily evidentiality in general. It is a reasonable hypothesis that evidentiality that is encoded by markers of tense and modality can more fruitfully be analyzed within a framework such as possible world semantics, which was developed to account for these categories' (Faller, 2002, 264).

${ }^{27}$ Kratzer $(1981,1991)$ does not explain how a 'conversational background' is formally selected from the context of the utterance, but she does suggest that the distinction between modals with epistemic and circumstantial modal bases may correlate with a difference in argument structure. As many have previously noted, there are good arguments that modals with a circumstantial modal base (i.e., root modals) have an implicit agent argument which can act as a syntactic controller, whereas epistemic modals are structurally speaker oriented.

${ }^{28}$ See also Garrett's (2002) analysis of the Tibetan indirect evidential.

${ }^{29}$ This analysis is similar to Kratzer's treatment of (modal) conditionals: for each world, the if-clause is added to the set of propositions the modal base assigns to that world, thus restricting the accessibility relation.

${ }^{30}$ See von Tiling's (1919) study for similar examples and contexts, based on the Isaaq dialect of Somali.

${ }^{31}$ Beyond linguistics (Jackendoff, 1983), there is an enormous literature concerning the relation between knowledge and (visual) perception in the related fields of philosophy of perception (Dretske, 1969, 1990) and neuropsychology (Milner and Goodale, 1995).

${ }^{32}$ On perceptual reports, see Higginbotham (1983a); on the relation between perceptual reports and evidentiality, see Van der Does and Lambalgen (2000).

${ }^{33}$ This is a feature of many languages with grammatical evidentials. According to Faller (2002, 123), the Qechua evidential $m i$ encodes direct evidence. The same evidential value is implicated by simple assertions. From a typological perspective (e.g. De Haan (to appear)), many languages only have overt evidentials for indirect evidence types, and in those cases, zero is interpreted as direct evidence. In languages that make the distinction between visual and nonvisual direct evidence, evidence by seeing is the default evidential.

${ }^{34}$ See Goodale and Milner (1992), Milner and Goodale (1995).

${ }^{35}$ I refer here to the cognitive mechanisms underlying temporality and evidentiality, not the historical evolution of grammatical forms. Diachronically, evidential meanings are often acquired by modal, tense and aspect morphemes (Bybee et al., 1994). Among languages with (sentential) evidentials, visual evidentials typically derive from already grammaticalized tense or aspect morphemes, or demonstratives (see De Haan, 1998, to appear) 